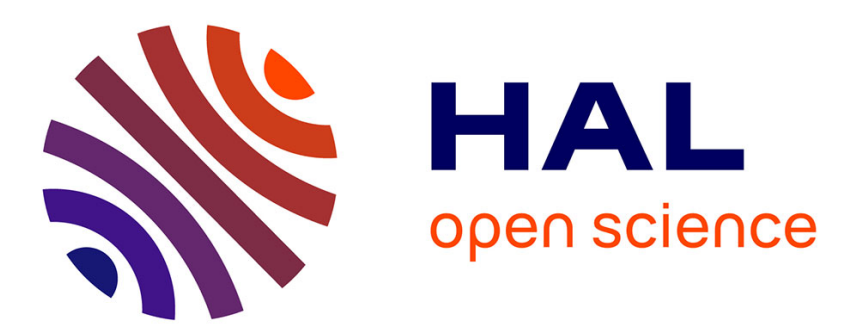

\title{
Validation of a digital interface for assessment of motor function based on MFM
}

Adriana Gomes Lisboa de Souza, Dominique Vincent-Genod, Carole Vuillerot, Michel Dubois, Guillaume Thomann

\section{- To cite this version:}

Adriana Gomes Lisboa de Souza, Dominique Vincent-Genod, Carole Vuillerot, Michel Dubois, Guillaume Thomann. Validation of a digital interface for assessment of motor function based on MFM. 1st International Conference on Human Systems Engineering and Design, IHSED2018, Oct 2018, Reims, France. hal-01925909

\author{
HAL Id: hal-01925909 \\ https://hal.science/hal-01925909
}

Submitted on 18 Nov 2018

HAL is a multi-disciplinary open access archive for the deposit and dissemination of scientific research documents, whether they are published or not. The documents may come from teaching and research institutions in France or abroad, or from public or private research centers.
L'archive ouverte pluridisciplinaire HAL, est destinée au dépôt et à la diffusion de documents scientifiques de niveau recherche, publiés ou non, émanant des établissements d'enseignement et de recherche français ou étrangers, des laboratoires publics ou privés. 


\title{
Validation of a digital interface for assessment of motor function based on MFM
}

\author{
Adriana Gomes L. de Souza ${ }^{1}$, Dominique Vincent-Genod ${ }^{2}$, Carole Vuillerot ${ }^{2}$, Michel \\ Dubois ${ }^{3}$, Guillaume Thomann ${ }^{1}$ \\ ${ }^{1}$ Univ. Grenoble Alpes, CNRS, Grenoble INP2 ${ }^{2}$ G-SCOP, 38000 Grenoble, France \\ ${ }^{2}$ Service de Rééducation pédiatrique, L’Escale, Hospices Civils de Lyon, Lyon, France \\ ${ }^{3}$ Laboratoire Interdisciplinaire de Psychologie, Univ. Grenoble Alpes, Grenoble, France
}

\begin{abstract}
Patients with neuromuscular diseases undergo frequent motor assessments. The MFM scale (Motor Function Measure) is a validated scale for all neuromuscular diseases. Tasks 18, 19, and 22 have the potential to have a digitized version on a Tablet. This article proposes to digitalize a first version of items 18, 19 and 22 based on MFM. The results show that the scores were similar for the Tablet version and the paper version.
\end{abstract}

Keywords: Digital Tablet · Neuromuscular disease · MFM Scale ·

\section{Introduction}

Neuromuscular disorders include a diverse group of diseases that cause muscle weakness and atrophy, leading to motor impairment of varying intensity [1]. Patients with significant motor loss progressively presented atrophy of distal predominance, significant deformity of the feet bilaterally and often weakness of the hand muscles which may limit daily life activities influencing quality of life [2].

The motor assessment of patients with neuromuscular disorders should be performed frequently, and the MFM - Motor Function Measure is an assessment applicable to all neuromuscular diseases, developed to highlight the clinical course of the patient and the patients therapeutic effects $[3,4,5]$. Although the motor assessment scales are practical and easy to apply. These measurement instruments present the disadvantage of the lack of accuracy of the score given during the exercise [6]. The kinematic study of human movement is an ongoing research topic that plays a key role in understanding musculoskeletal pathologies, mild traumatic brain injury, ergonomics, and athletic performance [7]. The technology applied to medicine has revolutionized the processes of diagnosis and treatment of diseases, with the aim of improving and prolonging the life of patients, as well as simplifying and accelerating the work of health professionals. With the development of tablet and Smartphone technologies, these devices have become not only very popular but also have a growing potential for hand therapy applications. Applications on the Tablet allow access to

\footnotetext{
${ }^{2}$ Institute of Engineering Univ. Grenoble Alpes
} 
fine motor skills and are easily customizable based on user need. In this way, this article proposes to validate the user-centered tablet technology for an MFM based hand motor assessment. This step allows identifying the needs and expectations of the therapist and the patient.

\section{Review}

Currently, the most effective tools for capturing hand movement are electromechanical devices or magnetic sensors (data gloves) [8, 9, 10, 11]. Despite the great accuracy of the data they have the disadvantages in terms of occasional use because they are very expensive, they hinder the natural movement of the hand and require complex calibration and configuration procedures to obtain accurate measurements.

With the recent arrival of 3D infrared sensors, devices like Microsoft Kinect and Leap Motion can recognize body gestures, allowing a new, more natural and intuitive, form of interaction than previous solutions. For applications that require only hand movement recognition, Leap Motion is one of the best options. According to [12], for a measurement and correct hand detection with Leap Motion, the fingers of the hand should be visible and separate. The hands should not be in contact with each other and the "broken wrist" hand posture is not recommended. The hand should always be maintained in wide and fluid movements, which limits the studies with neuromuscular patients.

The tablets arrived in early 2010 with the launch of Apple's famous IPad. They have been widely accepted by the public and became a technological trend for years to come. The tablet is a portable computer with a user interface built around a screen. Its multi-touch display makes the device responsive to various taps and has the potential to develop specific applications for patients with motor disabilities. Another advantage of using this technology is the ability to develop different applications (software) based on user needs, since they have open platforms providing the creation of specific applications and motivating users.

In the medical context, Tablet research has shown a potential applicability in the treatment of the hand of patients with Parkinson's disease and patients with sequelae of stroke [13, 14]. Applications developed for strength and dexterity training were considered effective and motivating for young patients [15]. While not making direct measurements, dexterity can be judged by the quality of the line left on the screen. The speed, acceleration and execution time of the drawings / tasks can also be related to the degree of loss of functionality of the hands [16].

In the MFM scale, 6 items are defined to evaluate the distal motricity of the upper limbs. Three of these items (item 18, item 19 and item 22) have been selected to be performed on the screen of a Tablet. The purpose of this research is to verify if the realization of these items through the Tablet would cause great changes in the MFM protocol, which has already been validated with the use of simple materials like paper, pencil and a CD $[17,18]$. 


\section{$3 \quad$ Material and Method}

\subsection{Choice of technology}

The Tablet selected for the development of the application has a Multi touch screen. Its advantages are the use of a lightweight precision pen and physical attributes such as screen area and thickness. Storage, processing capacity and price are also considered.

\subsection{Software}

Software development is based on the tasks that must be performed in the three MFM items, considering the initial phase, the objects needed to perform the task and the rules. In MFM, the patient has the right to make 2 attempts for each item. The therapist's requirement for simple and fast interfaces were also considered.

\subsection{Measured}

Patients with neuromuscular diseases were included in the study by the physician during the follow-up visit to 3 France assessment centers. Patients have the right to object the participation in the study. If the patient is a minor, he will be informed with his parents about the study. During the proposed MFM assessment, patients would perform items 18, 19, and 22 twice: once in the conventional manner and the other on the Tablet. The order of execution between the paper support and the support of the digital tablet was made at random, fixed by the software created. The therapists who were part of the study were informed of the protocol and procedures with the Tablet.

\section{$4 \quad$ Results}

\subsection{The Tablet}

An investigation was conducted to make the choice of the Tablet. For this study, ASUS Zen Pad 3S 10 was chosen. It passed in multi-touch tests made by the Android Multi Touch Benchmark Test application, which shows all touch screen information (size, pressure, location and number of touches). The price is reasonable compared to its technology. This tablet allows you to use the Z Stylus precision pen.

\subsection{Software development}

A first version of the software was developed based on the MFM evaluation process. A protocol of measures was developed by the therapists from Lyon, France, and several modifications were suggested to make the software easy and quick to use. 
Many changes have been made to avoid improper use of buttons and remedy the limitations of technology.

In the final version of the interface, the therapist can modify the position of the drawing according to the patient's need. Only in item 19, the patient's drawn dashes on the screen are visible to avoid influencing the note. A clear button allows the therapist to erase the features of the demonstration. When validating the item, anything written on the Tablet screen, visible or not, will be stored in a PDF file, accessible outside the program.

\subsection{Measurement result with patient}

The total of 37 patients (19 females and 18 males) with NMD were part of this study. An overview of this population is given in Table 1.

Table 1. Population under study

\begin{tabular}{clrc}
\hline Sex & Female & 19 & \\
Male & 18 & \\
Diagnostic & 6 & $24,3 \pm 12,6$ years \\
& ASI & 4 & $15,6 \pm 23,8$ years \\
& CMT & 13 & $15,2 \pm 14,3$ years \\
DMD & 1 & 16 years \\
Muscular dystrophy & 4 & $23 \pm 18,87$ years \\
& Steinert disease & 4 & $9 \pm 26,25$ years \\
& Others Myopathy & 5 & $33.76 \pm 22.6$ years \\
\hline
\end{tabular}

ASI - Amyotrophie Spinale Infantile; CMT - Charcot-Marie-Tooth disease; DMD Duchenne Muscular Dystrophy.

The evaluation given to the exercises performed on the tablet were very similar to the evaluation given by the traditional method (exercise performed on paper). It can be seen from the graphs (Fig.1) that there was more disagreement at point 19. But the assumption that the distribution of data is equal between groups cannot be rejected by any of the following: (Wilcoxon Test) p-value $=0.157>0.05$ for Item 18 , p-value $=$ $0.058>0.05$ for Item 19 and p-value $=0.317>0.05$ for Item 22 (significance level $5 \%)$.
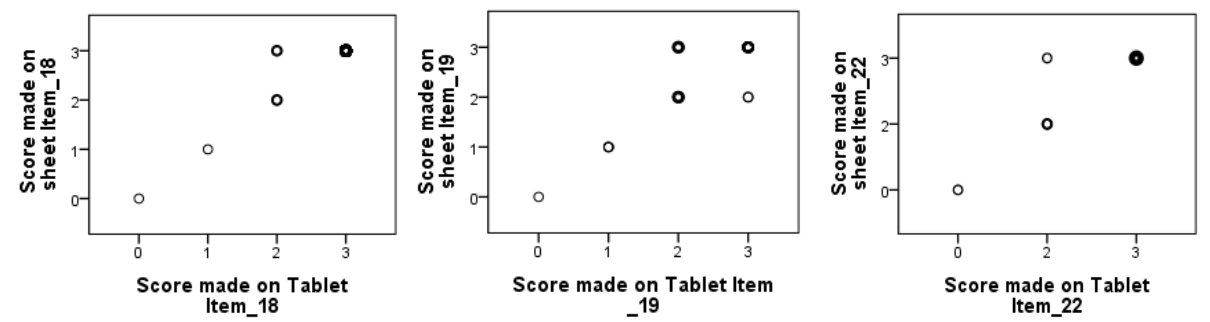

Fig. 1. Evaluation by the therapist for the three items - sheet and tablet comparison 


\section{$5 \quad$ Discussion and conclusion}

In this study, three of the 32 MFM items were proposed in a digital version in the Tablet, in order to first explore the potential of technology in the motor assessment process. According to [19], User-Centered Design is a process of collecting user data in order to create important feedback for designers. In this way, identifying the patient's needs to support the hand on the tablet screen while performing exercises and writing with a lightweight and precision pen were the most important criteria for choosing the tablet. The pen chosen offers enough precision and its weight is compensated by the flow of writing. However, the tremors are more exacerbated, and this is what has greatly disturbed the patients.

When comparing the scores of the three items in paper and digital - Tablet versions, similarities were observed. In addition, with the line records during the execution of the executions, the potential of the Tablet was verified as a tool for the therapist's assistance in the manual evaluation of MFM, which will be part of the continuation of this study. Overall application was well received and easily handled by patients and therapists after various modifications related to the practicality of the software. The child showed greater interest in performing the task on the Tablet.

This first step of choosing the tablet and using the software was very important to understand the limitations of the technology and understand the demands of both users. User feedback helped refine the restrictions and fix some design errors.

\section{Acknowledgments}

Eloïse GRONLIER, Eloïse LIOGIER, Ambre MIRC end Alison RODRIGUES LOUZANO

\section{$6 \quad$ References}

1. Urtizberea, J.-A.; Boucharef, W.; Frischmann, M. Maladies neuromusculaires: évolution des concepts médicos cientifiques et des pratiques de soins. Neuropsychiatrie de l'enfance et de l'adolescence, v. 56, n. 2, p. 51-57, (2008).

2. Mary, P.; Servais, L.; Vialle, R. Neuromuscular Diseases: Diagnosis and Management. Orthopaedics\&Traumatology: Surgery\&Research, (2018).

3. Vuillerot, Carole et al. Monitoring changes and predicting loss of ambulation in Duchenne muscular dystrophy with the Motor Function Measure. Developmental Medicine \& Child Neurology, v. 52, n. 1, p. 60-65, (2010).

4. Benaïm, C. et al. Analyse de validité de la «Mesure de la fonction motrice»(MFM) en pratique de consultation adulte d'un centre de référence pour maladies neuromusculaires. Revue neurologique, v. 166, n. 1, p. 49-53, (2010).

5. Montes, Jacqueline et al. Clinical outcome measures in spinal muscular atrophy. Journal of child neurology, v. 24, n. 8, p. 968-978, (2009).

6. Rodriguez-Blazquez, Carmen; Forjaz, Maria João; Martinez-Martin, Pablo. Rating Scales in Movement Disorders. In: Movement Disorders Curricula. Springer, Vienna, p. 65-75, (2017).

7. Dingenen, Bart et al. The assessment of movement health in clinical practice: A multidimensional perspective. Physical Therapy in Sport, (2018).

8. Fang, Bin et al. 3D human gesture capturing and recognition by the IMMU-based data glove. Neurocomputing, v. 277, p. 198-207, (2018). 
9. Foxlin, Eric et al. Motion tracking requirements and technologies. Handbook of virtual environment technology, v. 8, p. 163-210, (2002).

10. Placidi, et al. Overall design and implementation of the virtual glove. Computers in Biology and Medicine. v 43, n 11, p 1927-1940, (2013).

11. Shukor, et al. A new data glove approach for Malaysian sign language detection. Procedia Computer Science, v. 76, p. 60-67, (2015).

12. Coton, Justine et al. Etude de faisabilité de l'analyse de mouvement de doigts par le capteur LeapMotion. In: Conférence Handicap 2016-9ème édition. (2016).

13. Carabeo, Christle Grace G. et al. Stroke patient rehabilitation: A pilot study of an androidbased game. Simulation \& Gaming, v. 45, n. 2, p. 151-166, (2014).

14. Susini, J.; Pons, Olivier; Thevenot, C. Danse-doigts, jeu de motricité fine. Handicap 2016 La recherche au service de la qualité de vie et de l'autonomie, p. 81-86, (2016).

15. Kizony, Rachel et al. Tablet apps and dexterity: Comparison between 3 age groups and proof of concept for stroke rehabilitation. Journal of Neurologic Physical Therapy, v. 40, n. 1, p. 31-39, (2016).

16. Lin, Po-Chieh et al. A digital assessment system for evaluating kinetic tremor in essential tremor and Parkinson's disease. BMC neurology, v. 18, n. 1, p. 25, (2018).

17. De Lattre, Capucine et al. Motor function measure: validation of a short form for young children with neuromuscular diseases. Archives of physical medicine and rehabilitation, v. 94, n. 11, p. 2218-2226, (2013).

18. Bérard, Carole et al. A motor function measure scale for neuromuscular diseases. Construction and validation study. Neuromuscular disorders, v. 15, n. 7, p. 463-470, (2005).

19. Salvo,Michael J.Ethics of engagement: User centered designand rhetorical methodology. Technical Communication Quarterly. v.10, n.3, p. 273-290, (2001) 